\title{
Impact of Storytelling on Anxiety in 4-7 Year Old Children in Hospital: A Randomized Clinical Trial Study
}

\section{Ashrafalsadat Hakim*1, Seyedeh Mina Shafiey², Soodabeh Bassak Nedjad ${ }^{3}$, MohamadHossien Haghighizadeh ${ }^{4}$}

1. Instructor, Department of Nursing, Nursing Care Research Center in Chronic Diseases, Ahvaz Jundishapur University of Medical Sciences, Ahvaz, Iran

2. MSc in Nursing, Ahvaz Jundishapur University of Medical Sciences, Ahvaz, Iran

3. Associate Professor, Department of Clinical Psychology, Shahid Chamran University of Ahvaz, Ahvaz, Iran

4. Instructor, Department of Biostatistics, School of Health, Ahvaz Jundishapur University of Medical Sciences, Ahvaz, Iran

\section{Article Info \\ Received: \\ $2017 / 10 / 4$ \\ Accepted: $\quad 2018 / 01 / 20$ \\ Published Online 2018/03/16}

DOI:

10.30699/sjhnmf.26.3.155

Original Article

Use your device to scan and read the article online

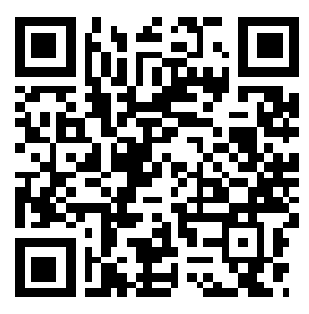

\section{Abstract}

Introduction: Storytelling is one of the appropriate methods to reduce anxiety in children admitted to hospital. The aim of this research was to investigate the effectiveness of storytelling in anxiety among 4-7 year old children who were admitted to hospital.

Methods: This research is a clinical trial. The samples were 40 children aged 4 to 7 years which were admitted at Ahvaz educational hospitals for different medical reasons. Prior to the intervention, the researcher examined the anxiety level of children according to the anxiety scale of the preschool children of Spence (parental form). After completing a research tool by mothers in both groups, the samples were randomly (Classified block) divided into two groups. Intervention group had 4 sessions of treatment (storytelling) for 20 minutes per each session at separate days. In the control group, only daily conversation was performed. The data analysis was done using descriptive and inferential statistical tests (Chi-square, independent t-test, and paired t-test). Then, the data were analyzed using SPSS20 at a significant level of $(P<0.05)$.

Results: The findings showed that there is a statistically significant difference between mean anxiety in two groups after intervention and storytelling caused anxiety reduction among hospitalized children compared to the children who had not received intervention $(P \leq 0.01)$.

Conclusion: Storytelling can reduce anxiety among 4-7 year old hospitalized children.

Keywords: Storytelling, Anxiety, Child, Hospitalization
Corresponding Information
Ashrafalsadat Hakim, Instructor, Department of Nursing, Nursing Care Research Center in Chronic Diseases, Ahvaz Jundishapur University of Medical Sciences, Ahvaz, Iran Email: hakim3448200@yahoo.com

Copyright (C) 2018, Sci J Hamadan Nurs Midwifery Fac. This is an open-access article distributed under the terms of the Creative Commons Attribution-noncommercial 4.0 International License which permits copy and redistribute the material just in noncommercial usages, provided the original work is properly cited.

How to Cite This Article:

Hakim A, Shafiey S M, Bassak Nedjad S, Haghighizadeh M H. Impact of Storytelling on Anxiety in Children 4-7 Years in Hospital: A Randomized Clinical Trial Study. Sci J Hamadan Nurs Midwifery Fac. 2018; 26 (3): $155-164$ 
مجله علمى دانشكده يرستارى و مامايى همدان - شايا الكترونيك: 19

مقاله يزوهشى

تأثير قصه گويى بر اضطراب كودكان P-V سال بسترىشده در بيمارستان:

مطالعة كار آزمائى بالينى

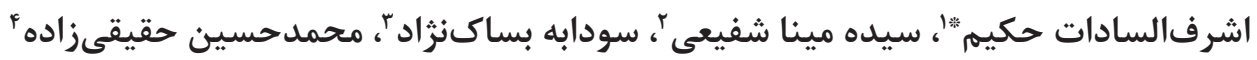

مربى، گروه يرستارى، مركز تحقيقات مراقبت يرستارى در بيمارىهاى مزمن، دانشكدة يرستارى و مامايى، دانشكاه علوم يزشكى

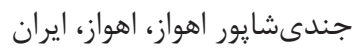

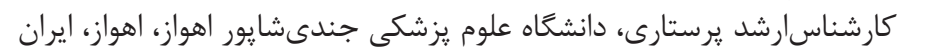

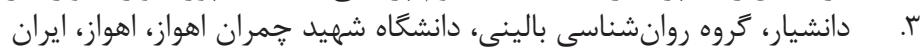

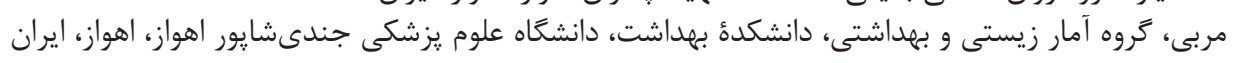

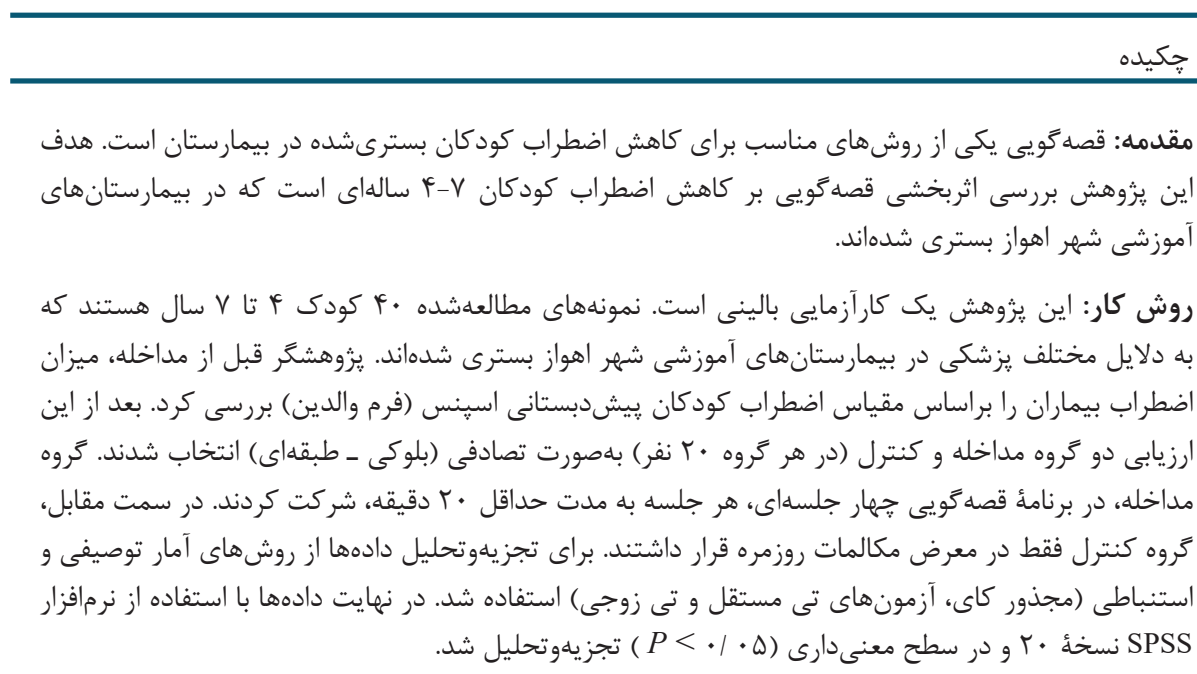

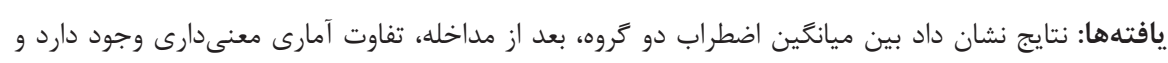

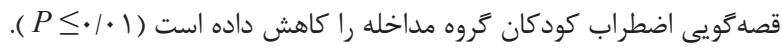

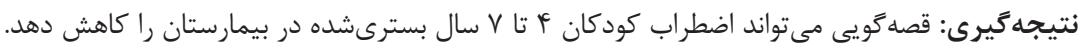
وازههاى كليدى: قصه گويى، اضطراب، كودكان بسترىشده، بسترىشدن در بيمارستان

اطلاعات مقاله

$$
\begin{aligned}
& \text { نويسندهُمسئول: } \\
& \text { اشرفالسادات حكيهم، } \\
& \text { مربى گروه يرستارى، مركز } \\
& \text { تحقيقات مراقبت يرستارى در } \\
& \text { بيمارى هاى مزمن، دانشكده } \\
& \text { يرستارى و مامايى، دانشگاه علوم ديماري } \\
& \text { يزشكى جندى شايور اهواز، اهواز، } \\
& \text { ايران } \\
& \text { يست الكترونيك: }
\end{aligned}
$$

hakim3448200@yahoo.com

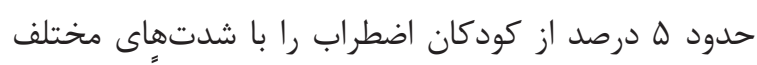

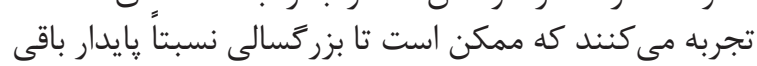

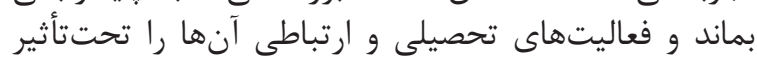

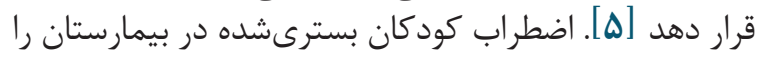

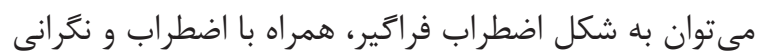

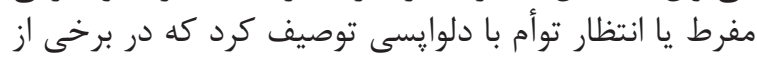

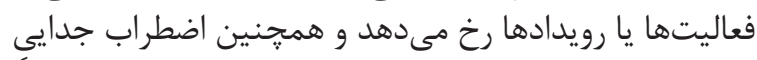

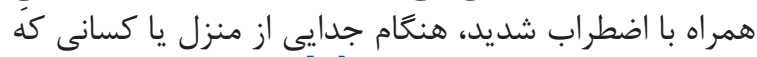

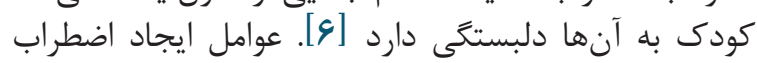

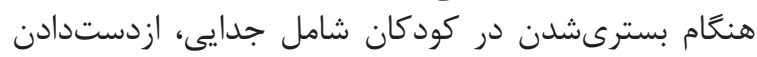

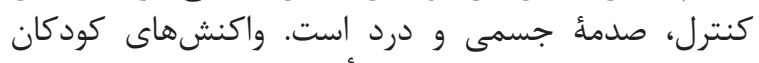
نسبت به اين بحرانها، تحت تأثير عوامل متعددى ماندى مانند

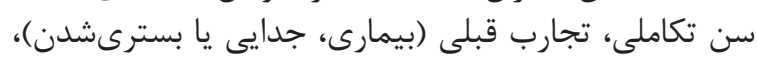

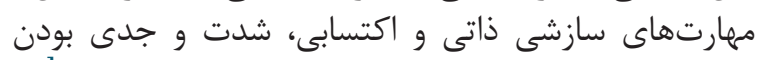

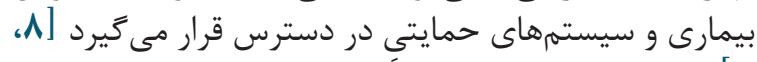

بسيارى از كودكان در مرحلهاى از دوران رشد خود بنا به ديه

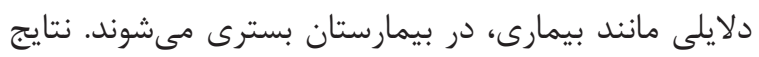

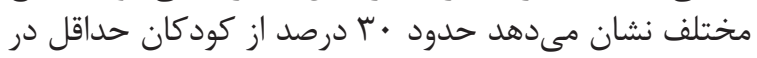

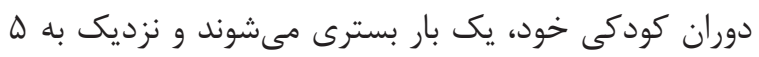

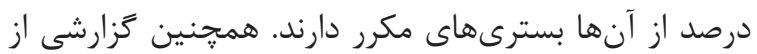

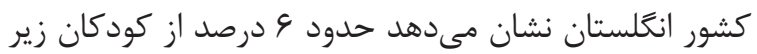

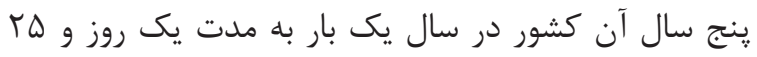

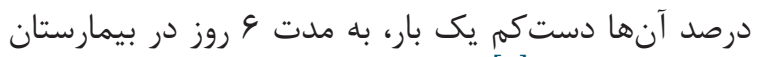

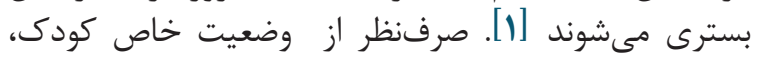

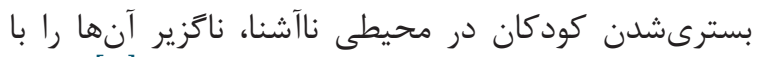

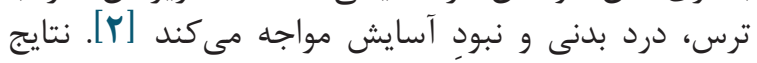

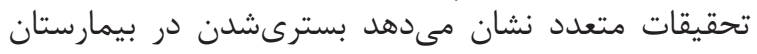

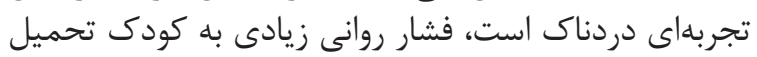

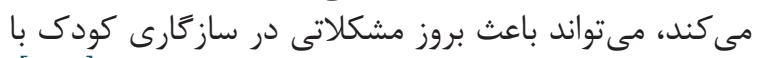

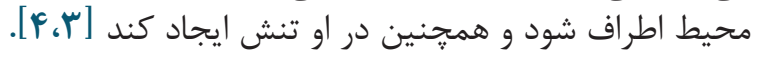




\section{روش كار}

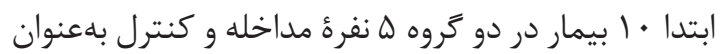

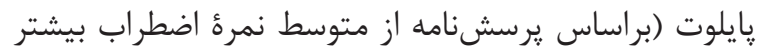

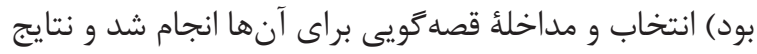

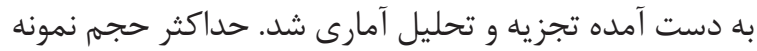

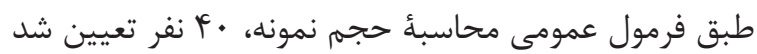

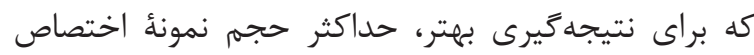

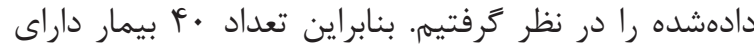

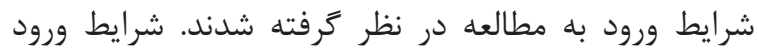

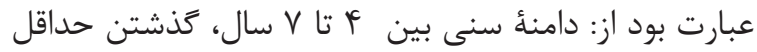

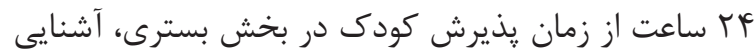

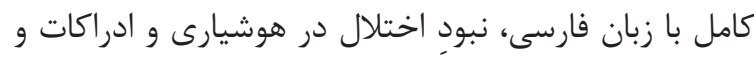

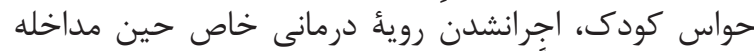

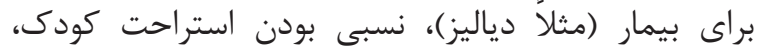

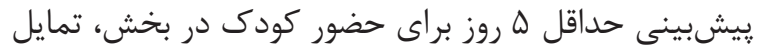

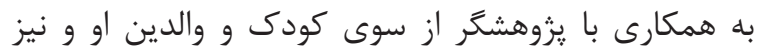

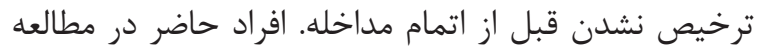

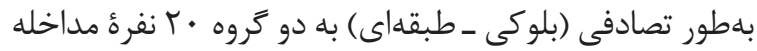
و كنترل تقسيم شدند.

ابزار كردآورى دادها دا در اين يزوهش شامل نامل فرم مشخصات

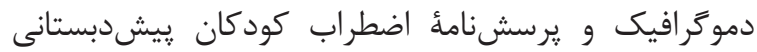

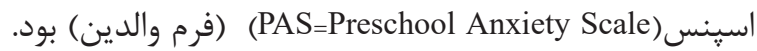

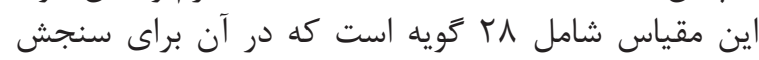

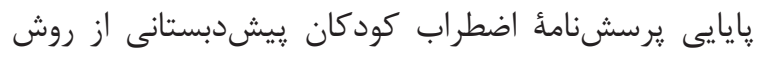

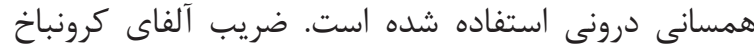

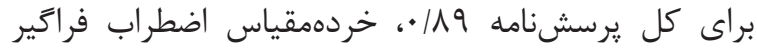

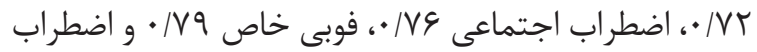

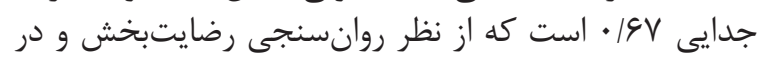

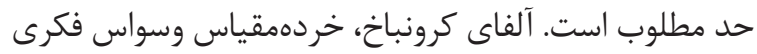

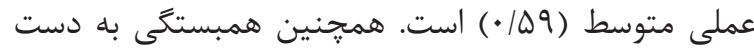

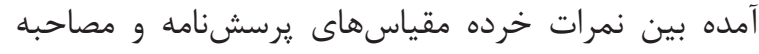

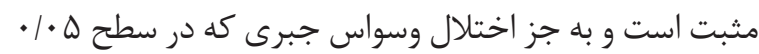

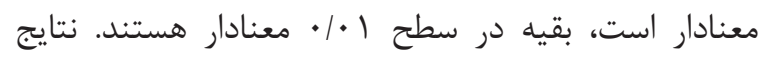

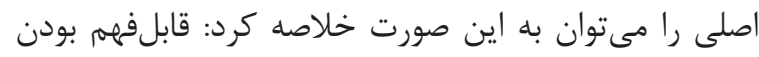

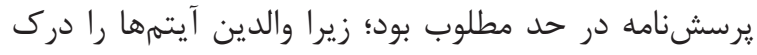

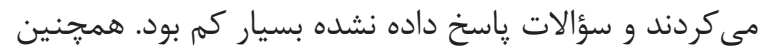

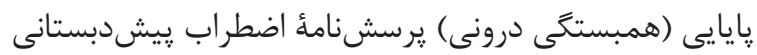

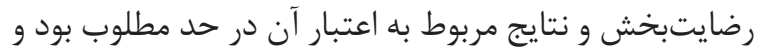

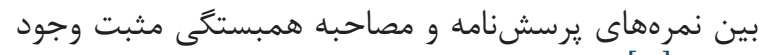
داشت [ه].

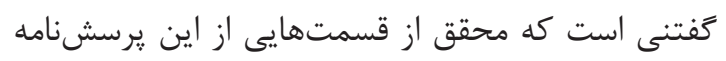

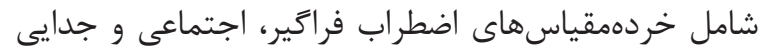

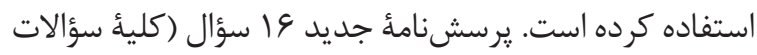

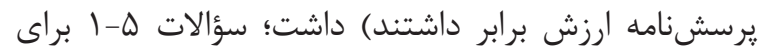

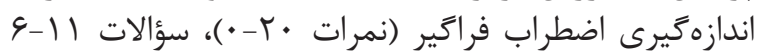

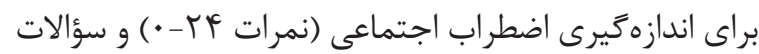

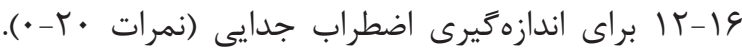

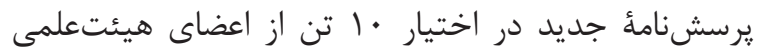

بيمارستان مىتواند روى بهببودى كودكان تأثير منفى بحذارد

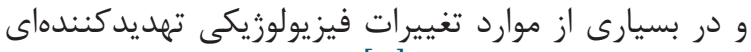

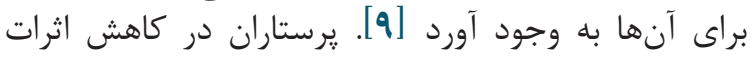

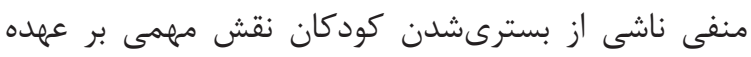

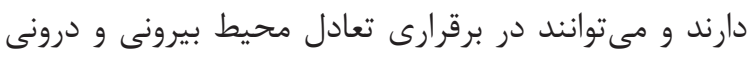

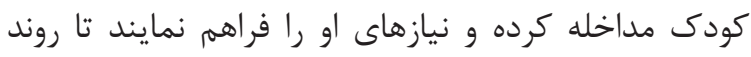

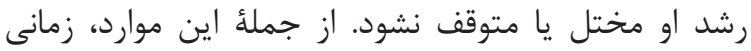

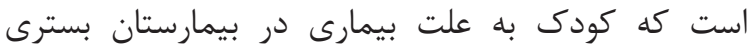

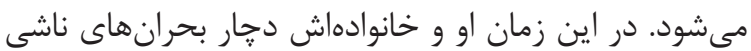

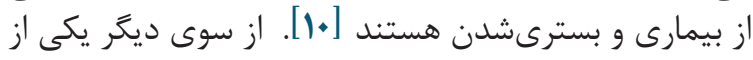

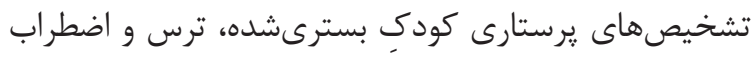

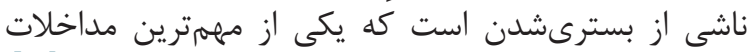

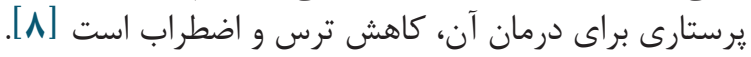

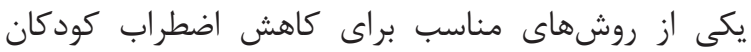

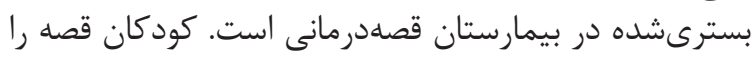

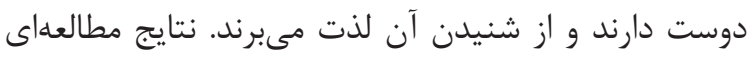

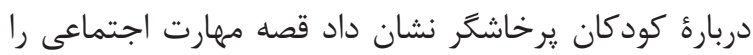

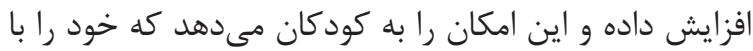

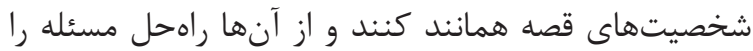

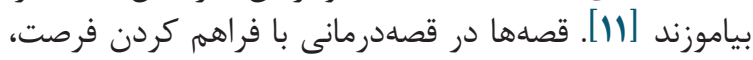

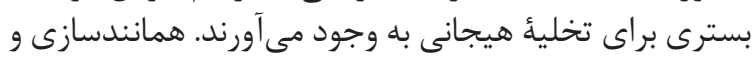

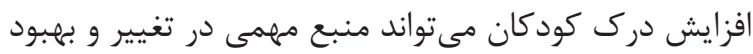

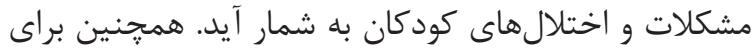

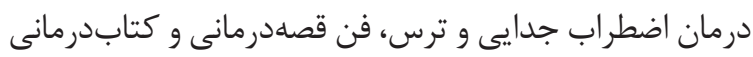

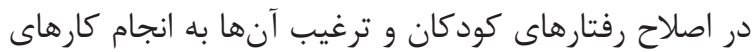

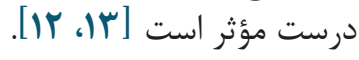

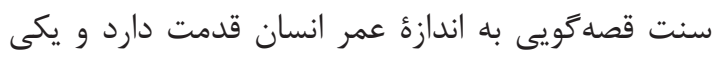

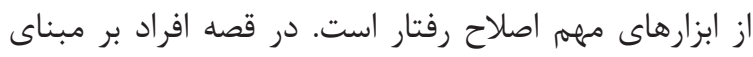

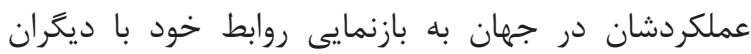

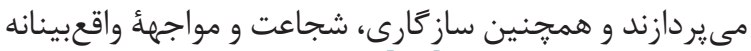

با مشكلات را مى آموزند [IF]

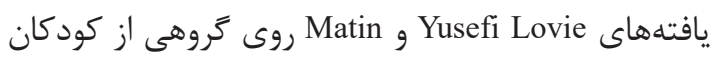

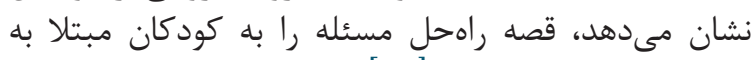

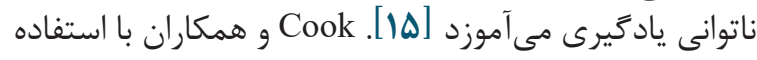

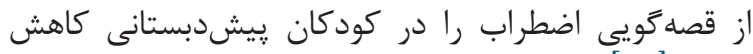

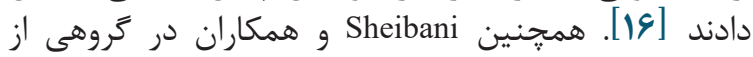

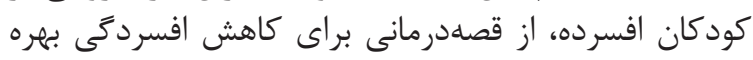

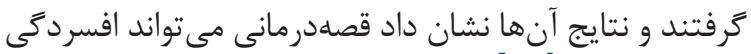

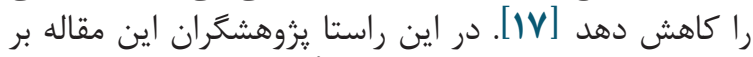

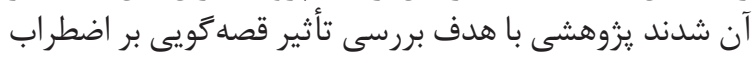

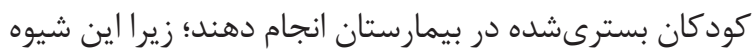

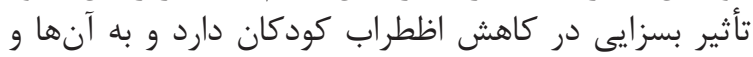

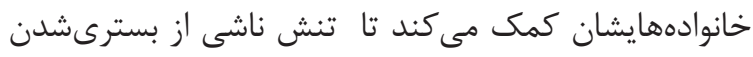

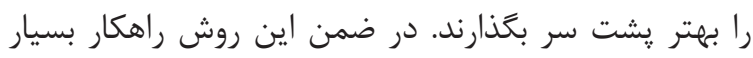

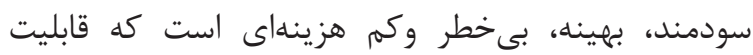

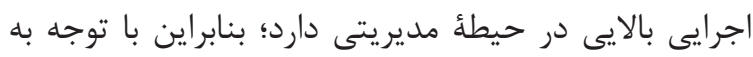

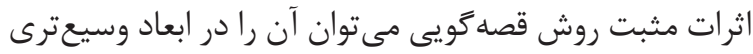

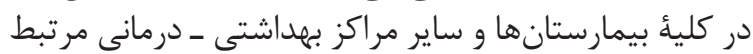

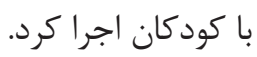




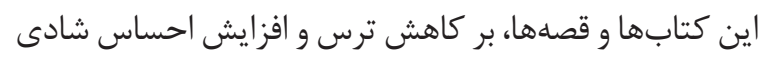

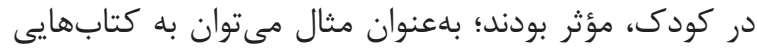

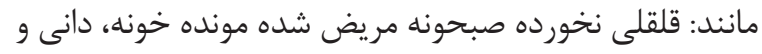

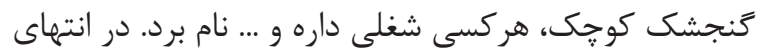

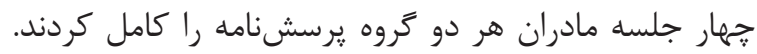

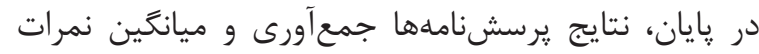

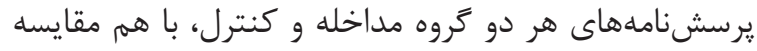

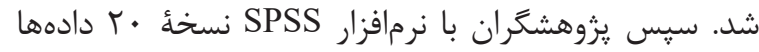

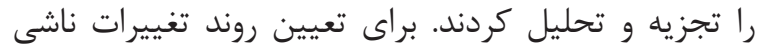

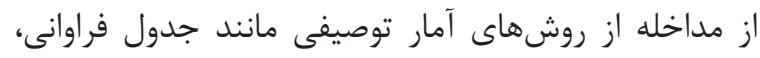

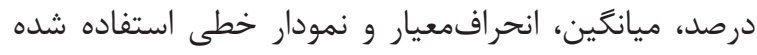

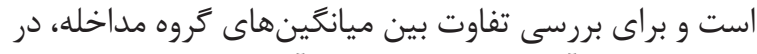

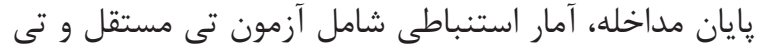

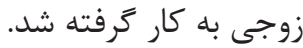

\section{يافتهها}

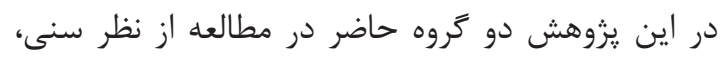

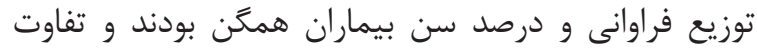

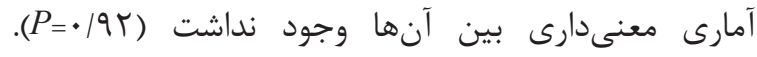

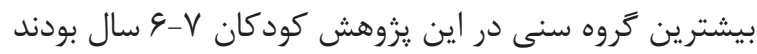

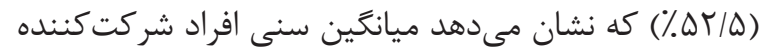

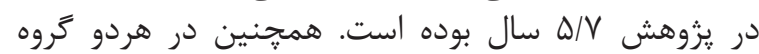

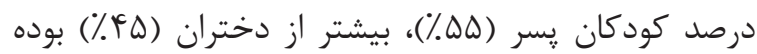

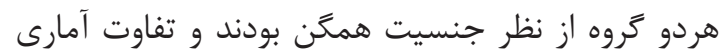

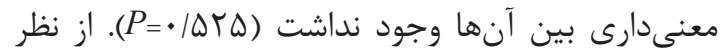

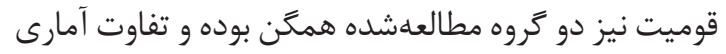

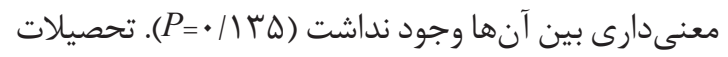

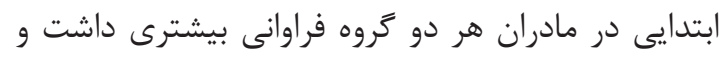

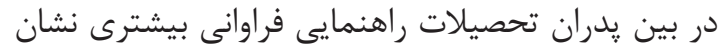

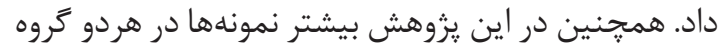

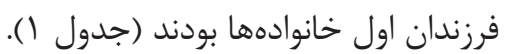

دانشكاه قرار داده شد و يس از أنأيد آنها استفاده شد.

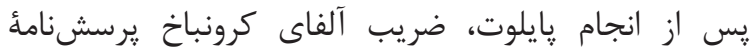

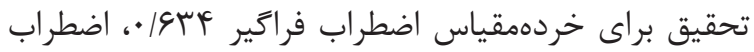

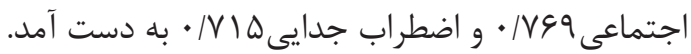

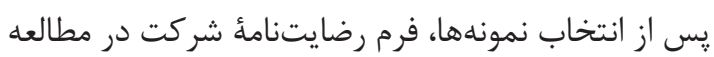

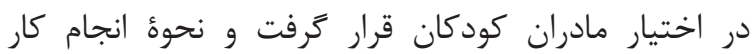

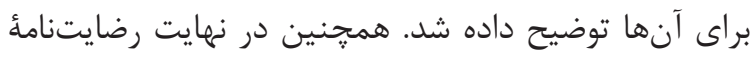

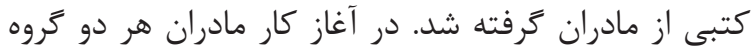

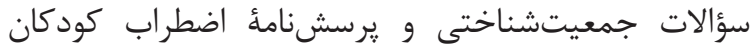

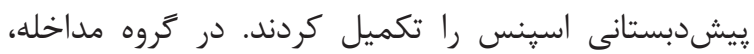

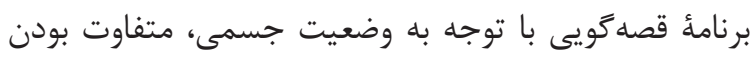

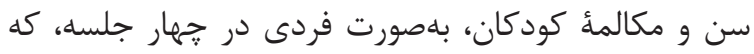

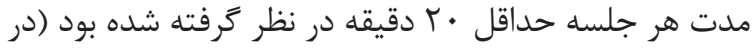

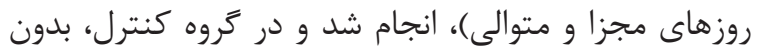

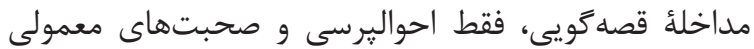

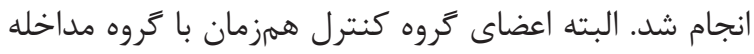

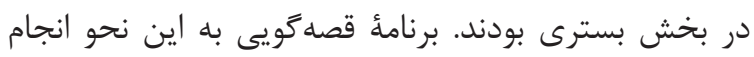

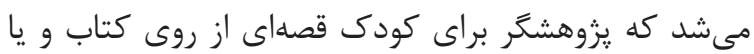

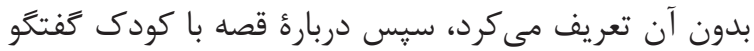

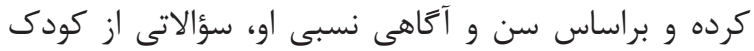

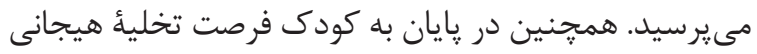

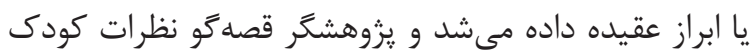

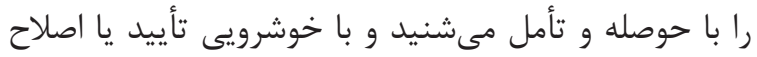

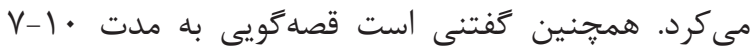

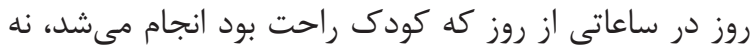

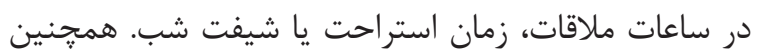

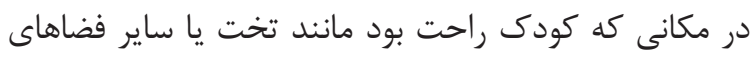

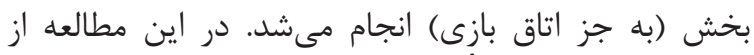

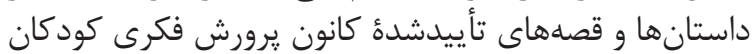

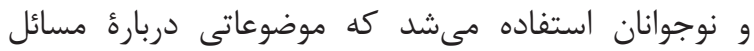
اخلاقى، بهداشتى، درمانى و ايمنى كودكان داشتنداند مضامين

و قوميت واحدهاى مطالعه به تفكيك دو كروه

تن جنسيت

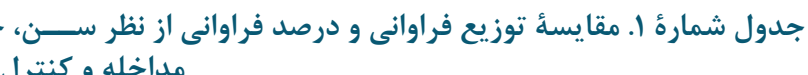

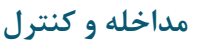

\begin{tabular}{|c|c|c|c|c|c|c|}
\hline$P$ Value & جمع جم & 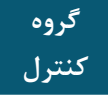 & كروه مداخله & \multicolumn{2}{|c|}{ نوزيع فراوانى (درصد } & \\
\hline \multirow{3}{*}{$P=\cdot / 9 T$} & $Q(Y Y / \Delta)$ & $\Delta(r \Delta)$ & $F(Y \cdot)$ & فراوانى (درصد) & $r-b$ & \multirow{3}{*}{ سن سن } \\
\hline & $1 \cdot(T \Delta)$ & $\Delta(r \Delta)$ & $\Delta(r \Delta)$ & فراوانى (درصد) & $\Delta-9$ & \\
\hline & $r)(\Delta r / \Delta)$ & $1 \cdot(\Delta \cdot)$ & $\|(\Delta \Delta)$ & فراوانى (درصد) & $4-V$ & \\
\hline \multirow{2}{*}{$P=\cdot \mid \Delta r \Delta$} & $1 \wedge\left({ }^{F} \Delta\right)$ & $\Lambda(\xi \cdot)$ & $1 \cdot(\Delta \cdot)$ & فراوانى (درصد) & دختر & \multirow[b]{2}{*}{ جنسيت } \\
\hline & $r r(\Delta \Delta)$ & $\mid r(\xi \cdot)$ & $1 \cdot(\Delta \cdot)$ & فراوانى (درصد) & 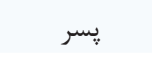 & \\
\hline \multirow{3}{*}{$P=\cdot / 1$ ז } & $1 \wedge(F \Delta)$ & $\mid r(9 \cdot)$ & $q(\Gamma \cdot)$ & فراوانى (درصد) & عرب & \multirow{3}{*}{ قوميت } \\
\hline & $1 \wedge\left(\varphi^{c} \Delta\right)$ & $\varphi(\Psi \cdot)$ & $\mid r(\varphi \cdot)$ & فراوانى (درصد) & فارس & \\
\hline & $F(1 \cdot)$ & $r(1 \cdot)$ & $r(1 \cdot)$ & فراوانى (درصد) & دو رگه & \\
\hline
\end{tabular}


بين ميانخين نمرات اضطراب جدايى كودكان، قبل و

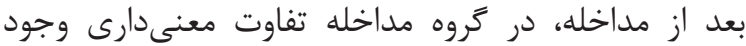

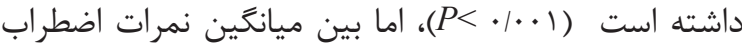

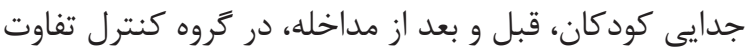
معنى دارى وجود نداشته است (

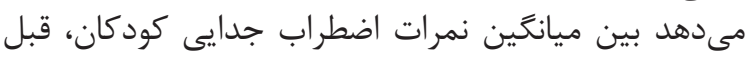

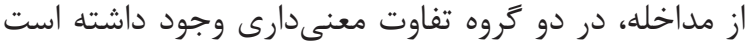

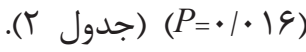

بين ميانگين نمرات اضطراب كلى كودكان، قبل و بعد از

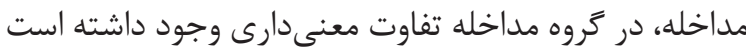

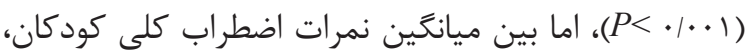

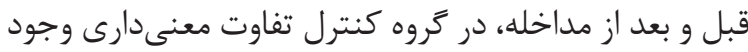
نداشته است (

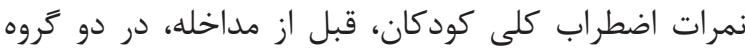

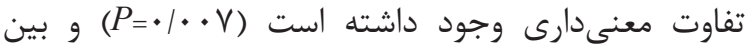

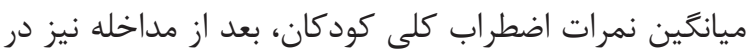

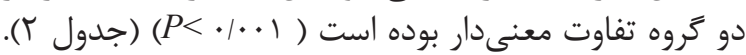

بين ميانگين نمرات اضطراب فراگير كودكان، قبل و بعد

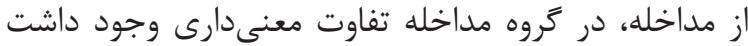

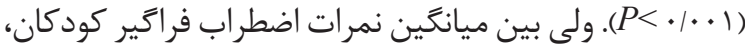

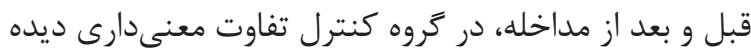

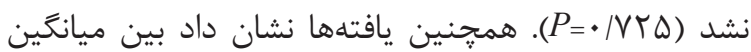

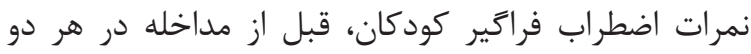
كروه تفاوت معنى دارى نبود (

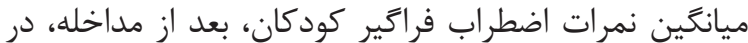

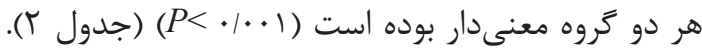
بين ميانگين نمرات اضطراب اجتماعى كودكان، قبل و و

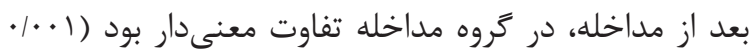

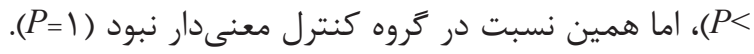

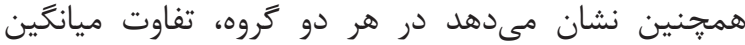

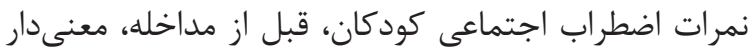

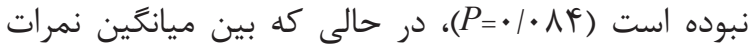

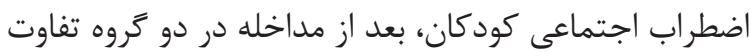

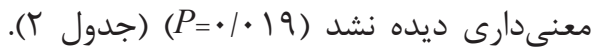

جدول شماره r. مقايسهٔ بين ميانغين نمرات اضطراب فراكير، اضطراب اجتماعى، اضطراب جدايى و اضطراب كلى كودكان، قبل و بعد

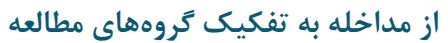

\begin{tabular}{|c|c|c|c|c|c|c|}
\hline \multirow{2}{*}{$P$ Value } & \multirow{2}{*}{ اختلاف ميانكَينها } & \multicolumn{2}{|c|}{ كنترل } & \multicolumn{2}{|c|}{ مداخله } & كروههاى مطالعه \\
\hline & & ميانخين & انحراف & ميانگين & انحراف & \multirow[b]{2}{*}{ اضطراب فراگير } \\
\hline$P=\cdot / r$ 凡 & $1 / \cdots$ & $\mid F / V$. & $r / T \cdot r$ & IT/V. & $r / \cdot 11$ & \\
\hline \multirow[t]{2}{*}{$P<\cdot / \cdot \cdot 1$} & $q / 4 \ldots$ & $\mid r / \lambda$. & מאוT & $\Lambda / \varphi$. & $r / T \Delta V$ & قبل - بعد \\
\hline & & \multicolumn{2}{|c|}{$P=\cdot / V r \Delta$} & \multicolumn{2}{|c|}{$P<\cdot / \cdots 1$} & $P$ Value \\
\hline$P=\cdot / \cdot \wedge F$ & $r / l \cdots$ & $|r| \cdots$ & r/fre & $\mid \Delta / 1$. & $F / \cdot r \Lambda$ & اضطراب اجتماعى \\
\hline \multirow[t]{2}{*}{$P=\cdot 1 \cdot 19$} & $r / l .$. & $|r| \cdots$ & $r / \Delta \Lambda F$ & $9 / 9 \ldots$ & $F / F \wedge \Lambda$ & قبل - بعد \\
\hline & & \multicolumn{2}{|c|}{$P=1$} & \multicolumn{2}{|c|}{$P<\cdot / \cdot 1$} & $P$ Value \\
\hline$P=.1 .19$ & $1 / V \cdots$ & $N / 1$. & $|/ F|$. & $9 / 1$. & r/GYA & اضطراب جدايى \\
\hline$P=.1 .9 \mathrm{~V}$ &.$/ 9 \cdots$ & $\Lambda / \cdot$ & I/ITF & $\mathrm{V} / \mathrm{l}$. & $1 / \lambda \cdot F$ & قبل- بعد \\
\hline & & .11 & $\cdot / \mathrm{V} / \Lambda$ & $r / V \cdots$ & $1 / 99$ & مقايسٔ اختلاف قبل \\
\hline & & & & & & $P$ Value \\
\hline$P=\cdot / \cdot \vee V$ & $r / \Lambda \cdots$ & $r \Delta / \Lambda$. & T/YGT & ऍN/G. & r/GVG & اضطراب كلى \\
\hline \multirow[t]{3}{*}{$P<\cdot / \cdot 1$} & $-1 \cdot / 4 \cdot$. & $r \Delta / \Lambda$. & $r / r \cdot r$ & $r \Delta / T^{*}$ & $r / V \cdot \varphi$ & قبل- بعد \\
\hline & & $\cdots / \cdots$ & $r / \cdot$ & $1 \pi / r$. & $r / 99$ & مقايسٔ اختلاف قبل \\
\hline & & \multicolumn{2}{|c|}{$P=1$} & \multicolumn{2}{|c|}{$P<\cdot / \cdots 1$} & $P$ Value \\
\hline
\end{tabular}




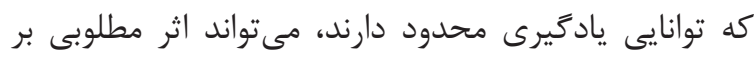

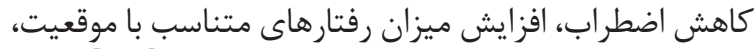

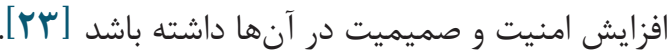

يافتههاى اين يروهش نشان داد بين ميانكين نمرات

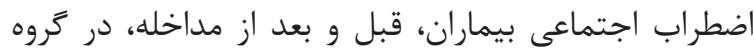

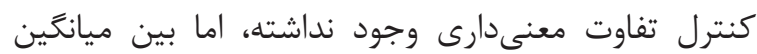

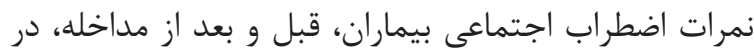

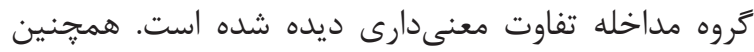

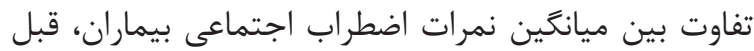

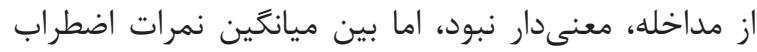

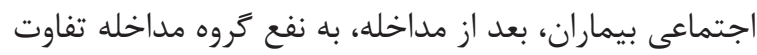

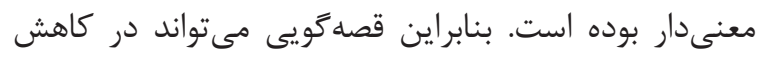

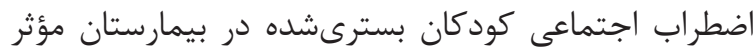

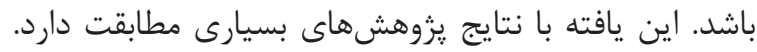

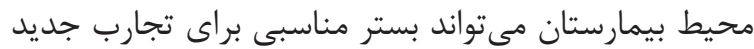

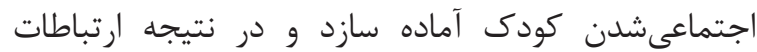

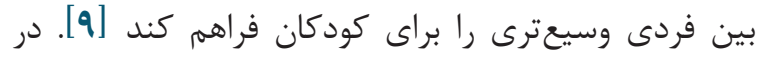

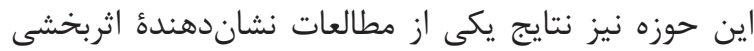

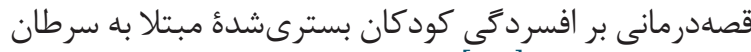

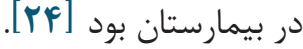

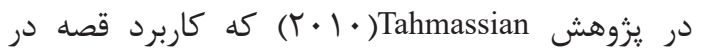
آموزش مهارتهاى اجتماعى به كودكان بر بهى شئ شده است،

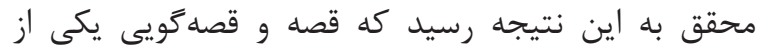

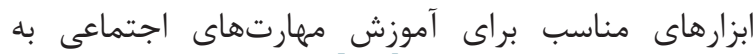

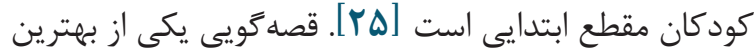

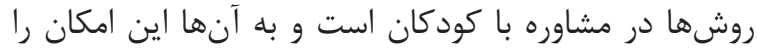

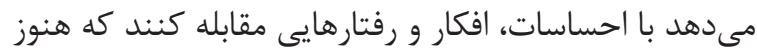

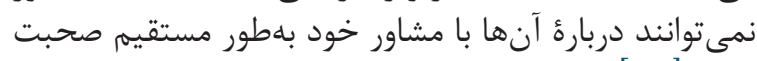

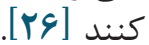

يافتههاى اين مطالعه نشان داد بين اختلاف ميانكَين

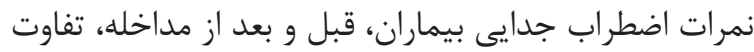

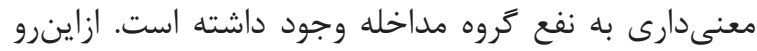

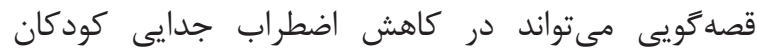

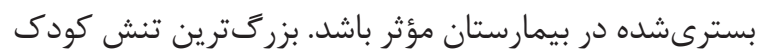

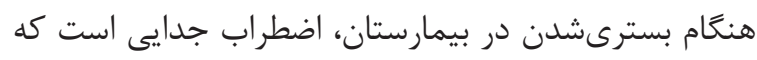

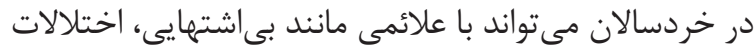

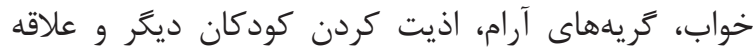

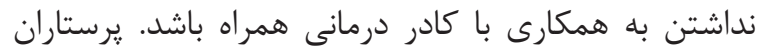

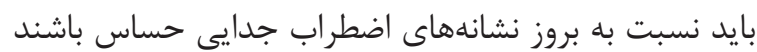

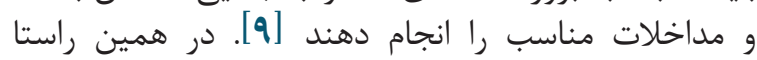

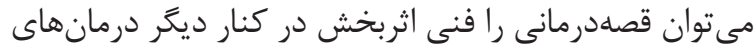

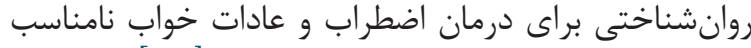

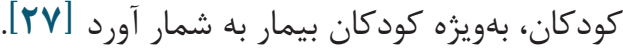

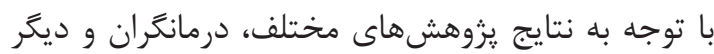

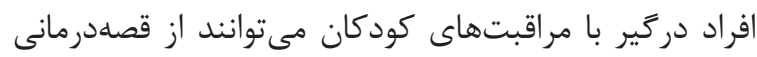

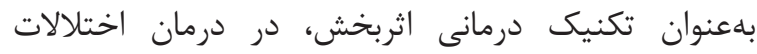

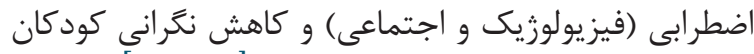

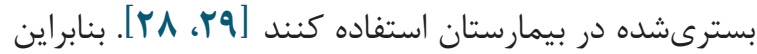

\section{تحث}

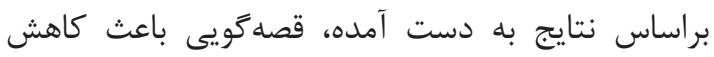

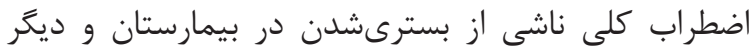

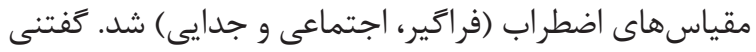

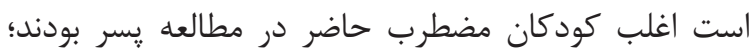

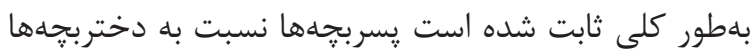

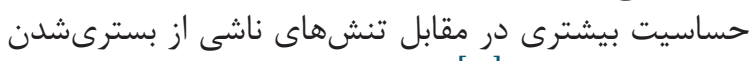

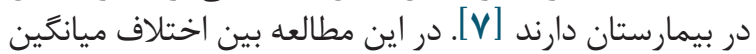

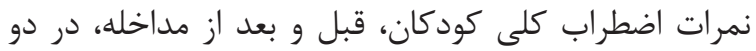

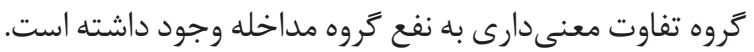

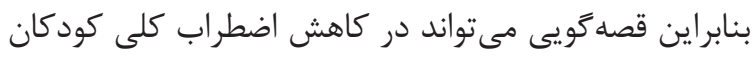

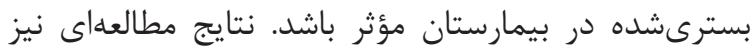

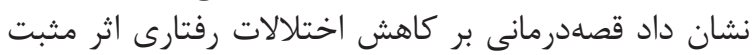

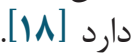

در : يزوهش Zadeh Mohammadi تأثير قصه و نمايشدرمانى بر اضطراب كودكان بىسريرست و

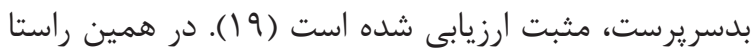

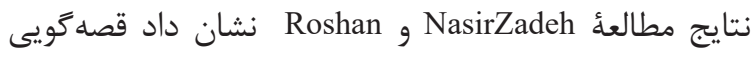

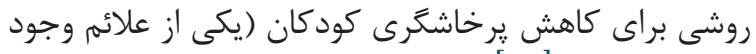

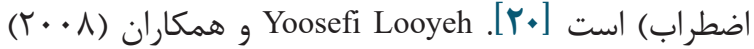

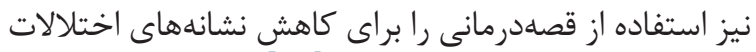

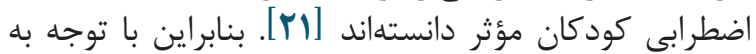

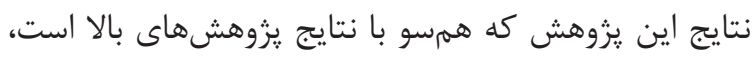

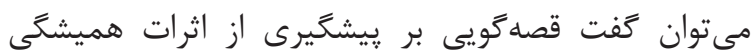

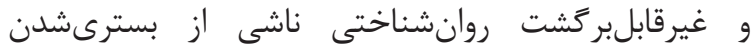

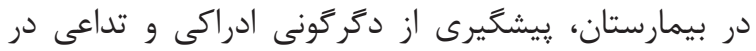

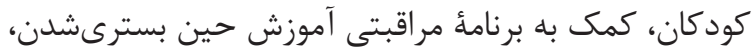

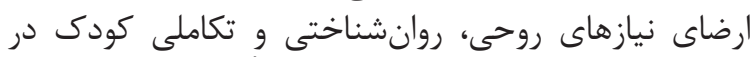

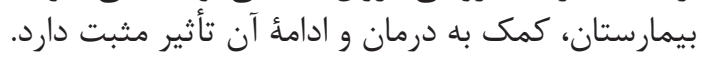
براساس يافتههاى اين يثروهش بين ميانغين نمرات

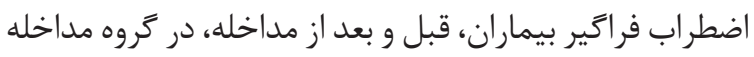

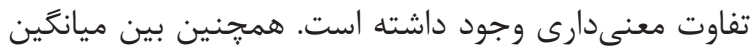

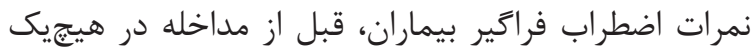

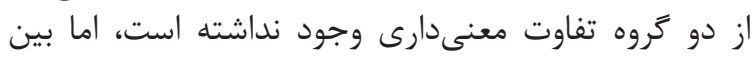

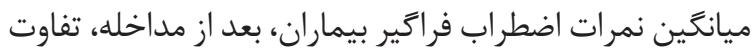

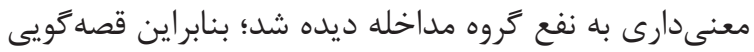

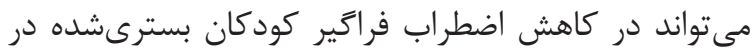

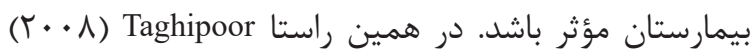

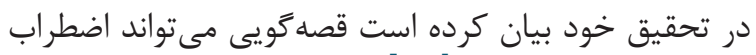

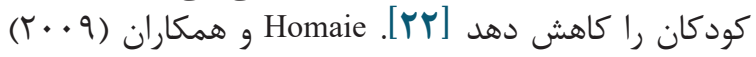

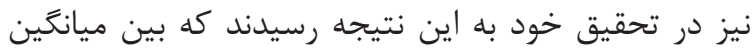

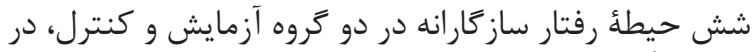

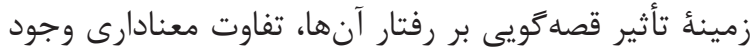

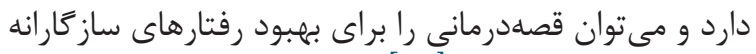

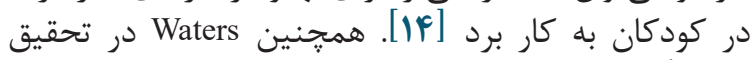
خود تأثير درمانى داستان بويسى ران را بر كودكانى كه به دانه دليل

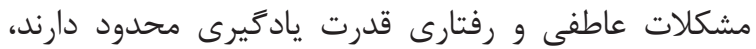
مثبت ارزيابى كرده و بيان ميى كند داستارى قدرت باديرى ميسى كودكانى 


\section{نتيجه گيرى}

براساس نتايج اين مطالعه، اثربخشى قصه كويى بر اضطراب

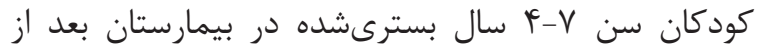

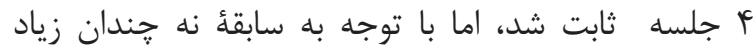

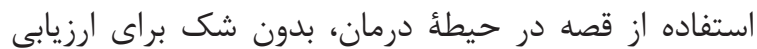

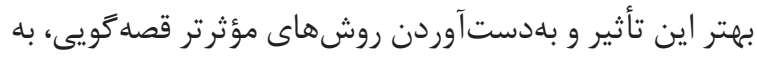

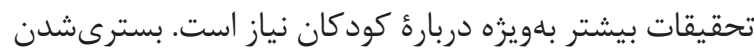

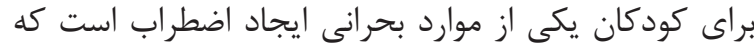

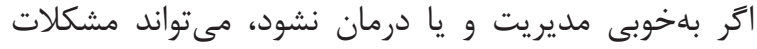

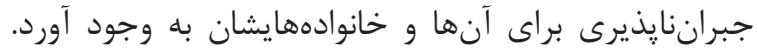

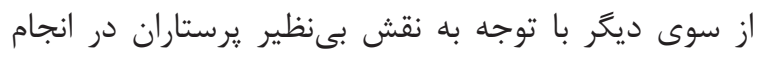

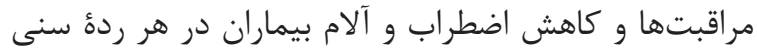

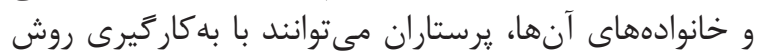

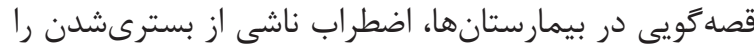

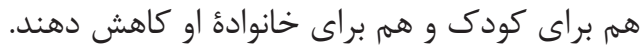

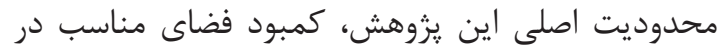

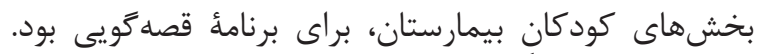

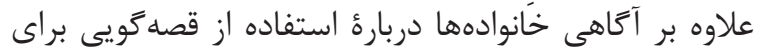

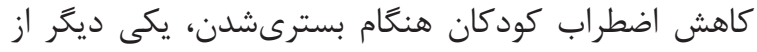

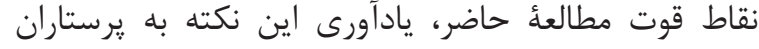

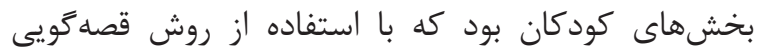

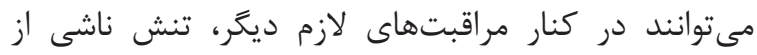

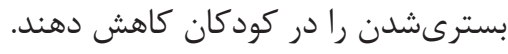

\section{سياسگزارى}

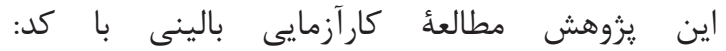

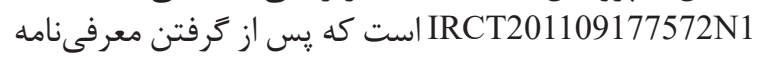

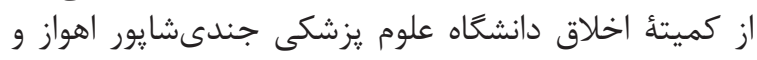

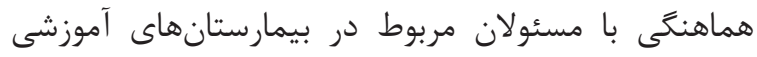

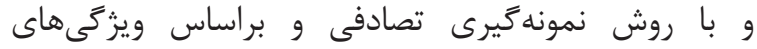

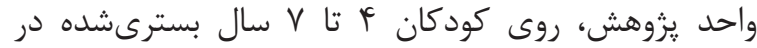

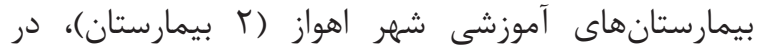

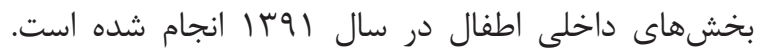

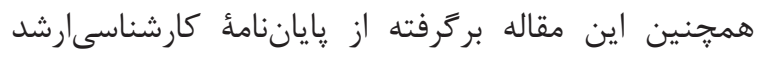

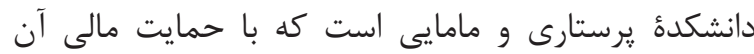

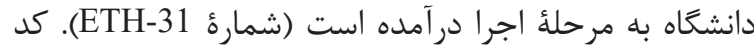

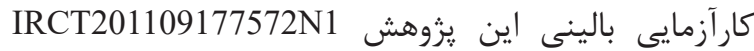

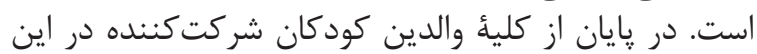

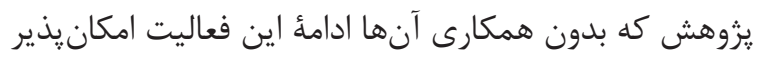

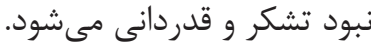

\section{تعارض منافع}

بين نويسندًان هيجَّونه تعارضى در منافع وجود ندارد.
نتايج به دست آمده از اين يزوهش با يافتههاى تحقيقات بالا

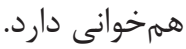

براساس يافتههاى اين مطالعه، بين ميانكين نمرات

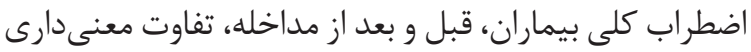

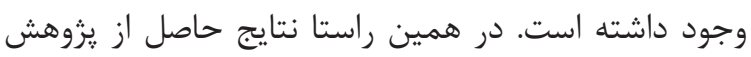

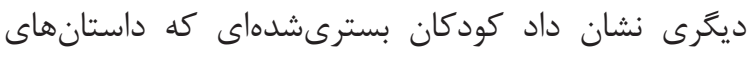

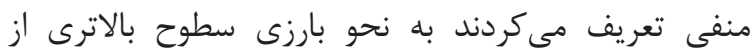

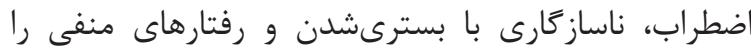

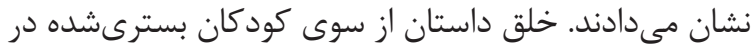

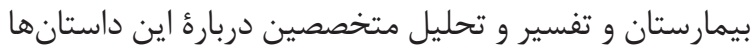

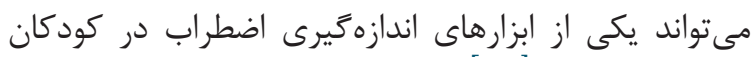

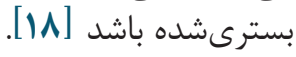

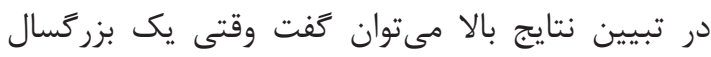

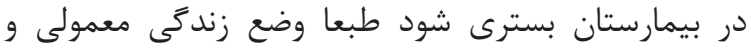

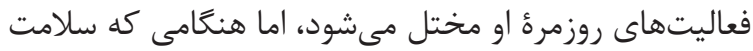

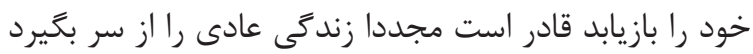

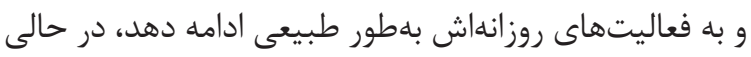

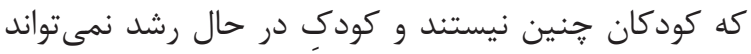

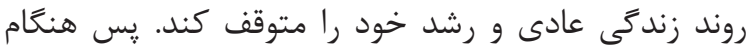

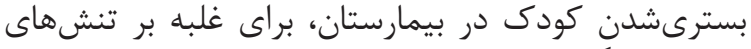

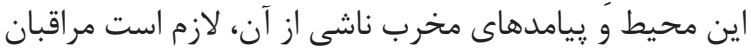

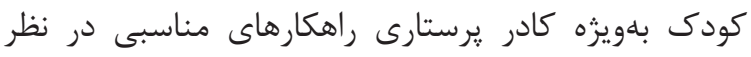

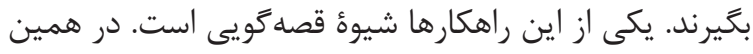

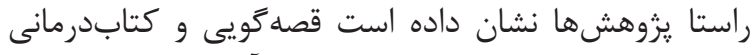

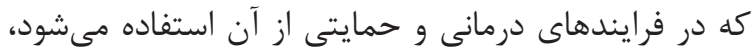

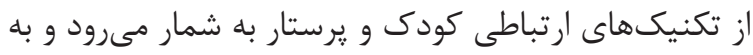

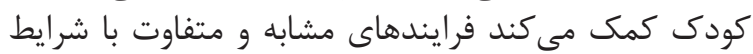

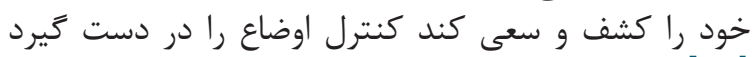

در سالهاى اخير قصهدرمانى بهعنوان يكى از فنى بنون

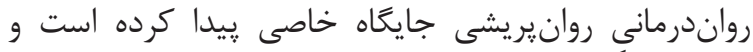

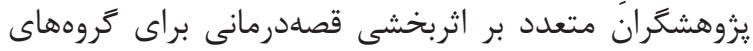

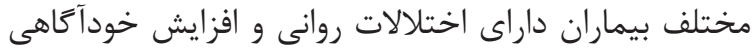

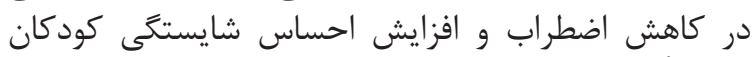

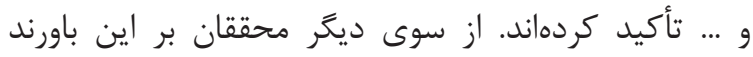

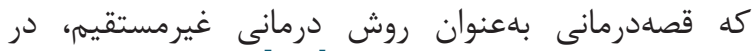

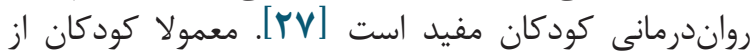

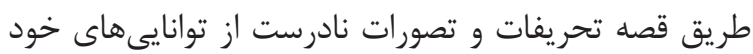

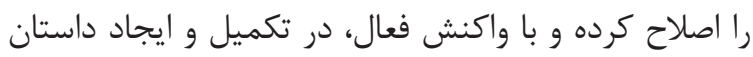

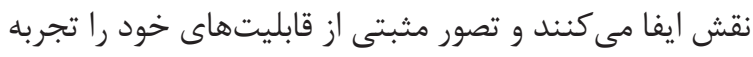

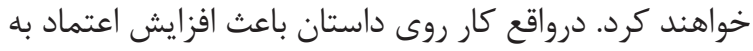

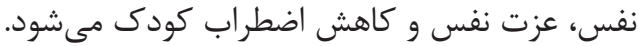




\section{References}

1. Rabiee M, Kazemi Malek Mahmodi S, Kazemi Malek Mahmodi S. The effect of music on the rate of anxiety among hospitalized children. Journal of Gorgan University of Medical Sciences. 2007 Oct 1;9(3):59-64.

2. Mamie YH., Alhani, F, Gofrani Pur F. Effect of Play program on anxiety in hospitalized schoolage children in Tehran Children Medical Center Tehran. Journal of Medical Science 2001; 4 (1): 55-62.

3. Clatworthy S, Simon K, Tiedeman ME. Child drawing: Hospital-An instrument designed to measure the emotional status of hospitalized school-aged children. Journal of Pediatric Nursing. 1999;14(1):2-9.

4. Kramer NA .Comparison of therapeutic touch and casual touch in stress reduction of hospitalized children .pediatric nursing, 1990; 165 (5): 483-485.

5. Bassak Nejad S, Poloie Shapurabadi F, Davoudi I. Efficacy of family anxiety management training of mothers with anxios kindergarden children aged between 4 to 6 years. Jundishapur Sci Med Journal. 2012; 11(4): 365-373.

6. Zahr LK. Terapeutic play for hospitalized pre scholars in lebanon. Pediatric nursing.1998; 23(5): 449-454.

7. Hockenberry Marilyn J, Wilson David. Familycentered care of the children during illness and hospitalization. Wong's Nursing Care of Infants and Children (2011), 9th Edition. Page 967.

8. Samela M, Salantera S, Aronen E: Child-reported hospital fears in 4-to 6 year-old children, Pediatr Nurse.2009; 35(5):269-276

9. Baily FC. Nurses perception of stress in pre-operative surgical patients. Journal of advanced Nursing. 1989; 14 (7): 575-581.https://doi. org/10.1111/j.1365-2648.1989.tb01593.x

10. Hejazi Farahmand S. Examine the factors that the children of school age are hospitalized pediatric hospitals of Tehran for their dissatisfaction [Dissertation] Tehran: Iran University of Medical Sciences. 1991.

11. Nasir Zadeh R, Roshan R. The effect of storytelling in reduction of aggression among boys between 6 to 8 years old. Journal of Psychiatry and Clinical Psychology of Iran 2010; 16(2):118-126.

12. Friedberg RD, Wilt LH. Metaphors and stories in cognitive behavioral therapy with children. Journal of Rational-Emotive \& Cognitive-Behavior Therapy. 2010;28(2):100-13.https://doi. org/10.1007/s10942-009-0103-3
13. Asgar Zadeh Salmasi F, Pur Sharifi H. The effect of storytelling on enhancement adaptation in conduct disorder children. Quarterly Journal of Education 2011; 4(14):13-24.

14. Homaie R, Kajbaf MB, Siadat SA. The effect of storytelling on a children adaptation. Psychological Study 2009; 5 (2):1-19

15. Yusefi Lovie M, Matin A. The Effect of Story Therapy on Coping Strategies of Children with Learning Difficulties. Journal of Research on Exceptional Children 2006; 20(2): 603-22.

16. Cook JW, Taylor L, Silverman P. The application of therapeutic storytelling techniques with preadolescent children: A clinical description with illustrative case study. Cognitive and Behavioral Practice, 2004; 11(2):243-248.

17. Sheibani S, Yousefi Loyeh M, Delavar A. The effect of narrative therapy on reducing depression in depressed children. Journal of Research in the field of Exceptional Children 2005; 6(4):916893.

18. Rajab Pours Farkhani S, Jahanshahi F. Story Therapy Effectiveness in Reducing Behavioral Disturbances. Journal of scientific and technical thinking and Child 2011; 2(2): 19- 35.

19. Zadeh Mohammadi A, Kalhor F. The effect of Story of drama therapy on the anxiety of orphan and abandoned Children. Proceedings of the First Congress of Art Therapy in Iran. 2007.

20. Nasirzadeh R, Roshan R. The effect of storytelling on aggression in six to eight-year old boys. Iranian Journal of Psychiatry and Clinical Psychology. 2010 Aug 15;16(2):118-26.

21. Yoosefi Looyeh M, Delavar A, Yoosefi Looyeh M. The Impact of Narrative Therapy on Amelioration of Anxiety Disorder Symptoms in Fourth Grade Students. JOEC. 2008; 8 (3):281-294.

22. Taghipoor S. The effect storytelling on depression and anxiety of orphan children, Master's thesis, 2008.

23. Waters trisha therapeutic storytelling:BRPS Action research projectreport university Sussex, 2001.

24. Karimi Nasab A, AghaMohamadian Shaarbaf HR. Narrative Therapy Efficacy on Depression in Children with Cancer. (Thesis MSc Clinical Psycology), Ferdosies

25. Tahmassian K. An application stories in teaching social skills to children, Proceedings of the First Congress of Iranian art therapy, martyr Beheshti University, Institute of the Family. 2010.

26. Yuosef PN, AghaYA.The Effect of Storytelling 
اشرفالسادات حكيم و همكاران. سعا

in Pain Reduction of Children with Leukemia. 2014;3(9): 82-96

27. Ajorloo M, Barghi Irani Z, Ali Akbari M. Story therapy effect on reducing anxiety and improvement habits sleep in children with cancer under chemotherapy. Health Psychology. 2016;5(18):525.

28. Zarei KH, Parandeh Motlagh Z, Seyedfatemi N, Khoshbakht F, Haghani H, Zarei M. Impact of storytelling on physiological, worry and social anxieties in hospitalized school-aged children.
Medical - Surgical Nursing Journal 2013; 2(3,4): 115-121.

29. Karami J, Momeni K, Mohammadi F, Shahbazi$\operatorname{rad} \mathrm{A}$. The effectiveness of narrative therapy for reducing symptoms of separation anxiety in children. JPEN. 2015; 1 (3):48-56

30. Velayati AA, Pouran S. Wongs Nursing Care of Infant and Children. 9th edition. Salemi publication; 2011. 
